\title{
The calibration analysis of soil infiltration formula in farmland scale
}

\author{
Tao QIAN, Na Na HAN*, and Shuan Ling CHANG \\ Department of Hydraulic Engineering, Tianjin Agricultural University Tianjin, China
}

\begin{abstract}
Soil infiltration characteristic is an important basis of farmland scale parameter estimation. Based on 12 groups of double-loop infiltration tests conducted in the test field of tianjin agricultural university west campus. Based on the calibration theory and the combination of statistics, the calibration analysis of phillips formula was carried out and the spatial variation characteristics of the calibration factor were analyzed. Results show that in study area based on the soil stability infiltration rate A calculate calibration factor $\alpha_{A}$ calibration effect is best, that is suitable for the area formula of calibration infiltration and $\alpha_{A}$ variation coefficient is 0.3234 , with A certain degree of spatial variability.
\end{abstract}

\section{Introduction}

Soil infiltration of rainfall, surface water, soil water and groundwater in the process of transformation is an important link, its infiltration characteristics is to design the ground irrigation and hydrological runoff calculation of an important base, in the migration of nutrients, many aspects, such as efficient utilization of water resources and hydrological conversion are of great significance. Many studies have shown that there is significant spatial variability in soil characteristics [1,2,3]. In terms of soil infiltration characteristics, domestic and foreign scholars have been using the traditional methods such as statistics, soil transfer function and calibration theory of spatial variation of soil infiltration characteristics and scale effect are analyzed, at the same time to study the different factors such as topography and land use ways for the influence of the spatial variation of soil infiltration characteristics, and some achievements have been made. Such as Bai meijian[4] studied the characteristics of spatiotemporal variability of soil infiltration during winter wheat growth under ground irrigation conditions. The spatial variation of soil stability infiltration rate in small watershed was studied by Yuan jianping[5].Jia hongwei[6] in Shiyang river basin, such as the establishment of a single parameter and soil infiltration model transfer function, for the soil infiltration characteristics on large scales of spatial variability study provides a method for reference; He Dan[7] systematically studied the spatial variation intensity, spatial variation structure and main variation sources of soil infiltration characteristics under different land use methods.However, the study on spatial variability of soil infiltration characteristics in field scale is relatively rare.Therefore, this paper studies the hydrological cycle experimental base of the west campus of Tianjin agricultural college. According to the small scale of farmland, soil infiltration test was carried out, and the soil infiltration law of small scale soil was analyzed, and the infiltration parameters were calibrated and the spatial variation characteristics were analyzed.

\section{Study area overview and test method}

The experiment was carried out in the experimental field at the west campus of tianjin agricultural college. The experimental field is located in the west suburb of tianjin, and the soil texture is light loamy soil, also known as tidal soil. Chao soil is a kind of zonal soil, by development of river alluvium materials under the action of groundwater formed half water into the soil, buried depth of groundwater in 1 to 1.5 meters, and with the rainy season and dry season lift, groundwater along the capillary can rise to the surface soil and soil have "night tide" phenomenon, so named chao soil. The soil in the western suburb of tianjin is a kind of moist soil, the soil color is mostly light brown, the PH value is 7.0-8.5, and the dry and wet alternation forms a lot of plastic film, embroidery pattern, rust stain, sand ginger, and a small amount of iron manganese nodules. The organic matter content of tidal soil is low, only about $1 \%$. According to the actual situation of regional topography, In the field of $60 \mathrm{~m} 80 \mathrm{~m}$ mtitian, it is selected to carry out the tworing infiltration method seepage test of the 12 series. And at each measuring point for collecting soil samples, determination of the initial soil water content (drying method), saturated water content (drying method), field capacity (two-ring infiltration method) and dry density (two-ring infiltration method). And record the temperature with a thermometer.

\section{Philip's empirical formula}

\footnotetext{
* Corresponding author: hnn23144@163.com.
} 
Philip (1957) puts forward the empirical formula of soil infiltration. A large number of studies have shown that the Philip formula is simple in form, with few parameters, and has a clear physical foundation. It can well describe the one-dimensional infiltration process under homogeneous short duration conditions. It has important application value. The formula is as follows:

$$
I(t)=S t^{\frac{1}{2}}+A t
$$

The infiltration rate $i(t)$ formula is as follows:

$i(t)=\frac{1}{2} S t^{-\frac{1}{2}}+A$

In the formula: $I(t)$ is the cumulative infiltration $(\mathrm{cm})$ on the unit area; $t$ is infiltration diachronic ( $\mathrm{min}) ; S$ is soil infiltration rate $\left(\mathrm{cm} / \mathrm{min}^{0.5}\right)$; $\mathrm{A}$ is a stable infiltration rate (cm/min).

In the initial stage of infiltration, parameter $S$ plays a major role, which is equivalent to horizontal infiltration. With the increase of infiltration time, parameter $A$ becomes the main factor affecting infiltration. When the Philip formula is applied to solve the problem, the infiltration parameters $S$ and A are often obtained by the field infiltration test.

\section{Results and Analysis}

\subsection{Calibration of Philip's empirical formula}

The theory of calibration is developed on the basis of the law of similarity, that is, the soil in the fields of the field is similar to each other and neglects the influence of other factors. The calibration principle for the Philip infiltration formula can be found in the literature [1]. According to the calibration principle, the following formula is used to calibrate the Philip infiltration type. as follows:

$$
\begin{gathered}
\alpha_{\mathrm{si}}=\left(S_{i} / \bar{S}\right)^{2} ; \alpha_{\mathrm{Ai}}=\left(\mathrm{A}_{i} / \bar{A}\right)^{1 / 2} \\
I^{\#}=\alpha I ; t^{\#}=\alpha^{3} / t
\end{gathered}
$$

In the formula, $i$ is the number of measuring points. $S i$ and $A i$ are the infiltration parameters of the corresponding measurement points. $\alpha_{S i}$ is based on the calibration factor value calculated on the basis of the imbibition rate $\mathrm{S}$, and $\sigma_{A i}$ is the calibration factor value based on the calculation of the steady seepage rate of $A$. The calibration factor of each test point is shown in Table $1 ; \alpha$ is the calibration factor, $I^{\#}$ and $t^{\#}$ are the cumulative infiltration and infiltration diachronic time after calibration, and $\mathrm{S}$ and $\mathrm{A}$ are the mean values of $\mathrm{S}$ and $A$, respectively. Using the next type calculation:

$$
\bar{S}=\frac{1}{n} \sum_{i=1}^{n} S_{i} ; \bar{A}=\frac{1}{n} \sum_{i=1}^{n} A_{i}
$$

Table 1 Infiltration parameters and scaling factors in survey points

\begin{tabular}{|c|c|c|c|c|}
\hline $\begin{array}{c}\text { Test } \\
\text { point } \\
\text { number }\end{array}$ & $\mathbf{S}(\mathbf{m m} / \mathbf{m i n} \mathbf{0 . 5})$ & $\mathbf{A}(\mathbf{m m} / \mathbf{m i n})$ & $\boldsymbol{\alpha}_{\mathbf{S}}$ & $\boldsymbol{\alpha}_{\mathbf{A}}$ \\
\hline 1 & 4.7105 & 0.1208 & 0.65065 & 1.41753 \\
\hline 2 & 2.5005 & 0.0046 & 0.18334 & 0.101393 \\
\hline 3 & 8.6744 & 0.6477 & 2.20644 & 1.203136 \\
\hline 4 & 10.892 & 0.7278 & 3.47879 & 1.275363 \\
\hline 5 & 14.028 & 0.8317 & 5.77039 & 1.363362 \\
\hline 6 & 2.8671 & 0.5096 & 0.24104 & 1.067192 \\
\hline 7 & 14.028 & 0.8317 & 5.77039 & 1.363362 \\
\hline 8 & 1.9611 & 0.3021 & 0.11264 & 0.821681 \\
\hline 9 & 0.6591 & 0.0201 & 0.01273 & 0.211946 \\
\hline 10 & 1.4098 & 0.0528 & 0.05828 & 0.343514 \\
\hline 11 & 1.3947 & 0.0214 & 0.05703 & 0.218693 \\
\hline 12 & 6.9528 & 1.2991 & 1.41753 & 1.703919 \\
\hline $\begin{array}{c}\text { Average } \\
\text { value }\end{array}$ & 5.8397 & 0.4475 & & \\
\hline
\end{tabular}

Type (3) and (4) is the calibration relation used in infiltration analysis. By introducing it into 1 (Philip), combined with the calibration principle, we can get the calibrated formula of infiltration in the study area.

$$
I^{\#}=5.8397 t^{\# 0.5}+0.4475 t^{\#}
$$

\subsection{Optimal selection of calibration factor}

According to the field measured data, the original cumulative infiltration curve of each measuring point is drawn, as shown in Figure 1. It can be seen from the diagram, Because of the spatial variation of soil soil infiltration characteristics, the seepage curves of each measuring point are very different, so calibration and analysis are needed.

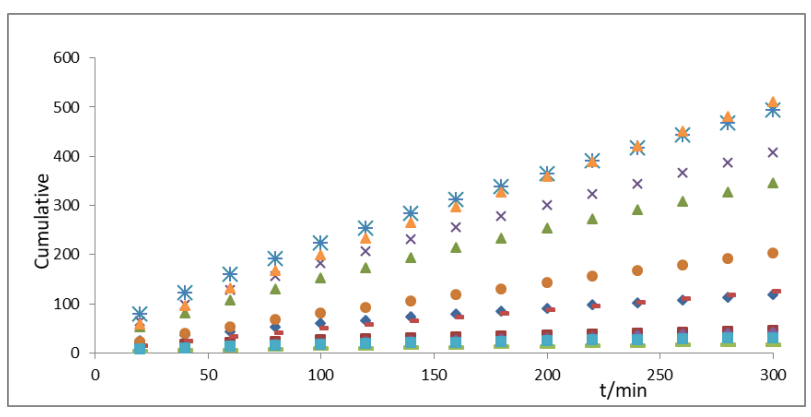

Fig. 1. Original cumulative infiltration curves of survey points

In order to obtain a better $\mathrm{I}^{\#}-\mathrm{t}^{\#}$ relationship for each test point, the spatial variability of infiltration parameters is studied quantitatively. By using the calibration factor $\alpha_{A}$ and $\alpha_{S}$ based on the infiltration parameters $A$ and $S$, the infiltration curves of each test point in the study area are calibrated. The results of the calibration are shown in Figure 2 and figure 3. It is visible from the diagram, There is a clear difference between the curve of the $\alpha_{s}$ calibration and the curve described in formula 6 , the effect of calibration is poor. The curve of the $\sigma_{A}$ calibration is not exactly the same as the curve described in formula 6 , but there is a high consistency, the effect of calibration is better. This is in line with the conclusions of Nie Weibo's [8] study. 


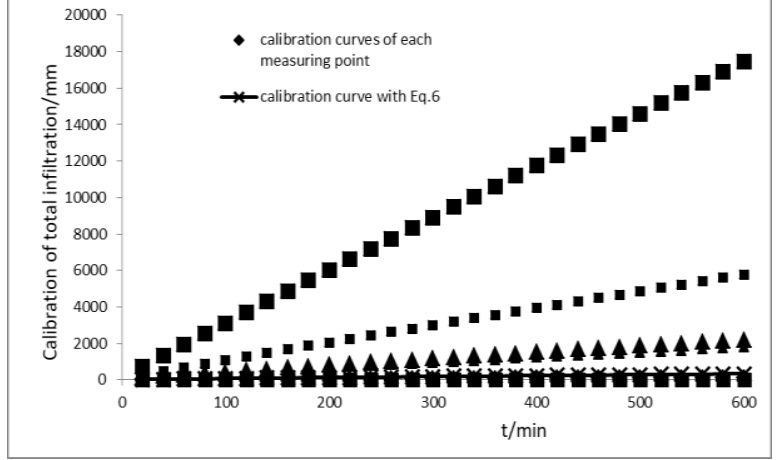

Fig. 2. ${ }^{\boldsymbol{\alpha}_{s_{\text {calibration }}} \text { curve and formula (6) curve }}$

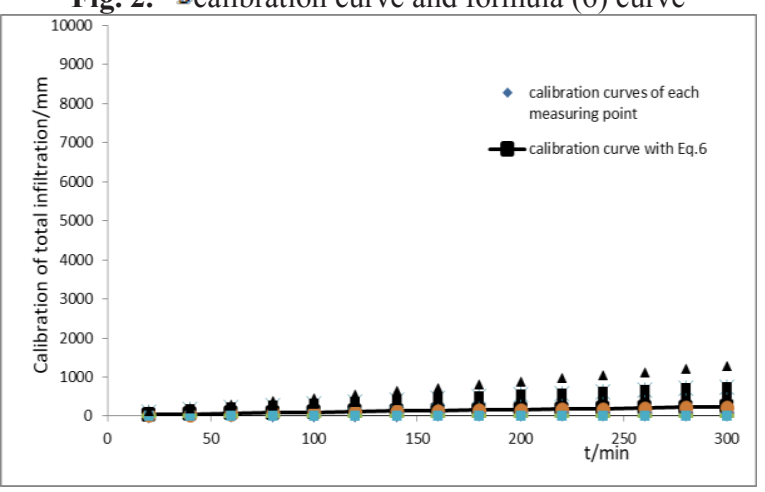

Fig.3. $\boldsymbol{\alpha}_{A \text { calibration curve and formula (6) curve }}$

Therefore, in practical application, ${ }^{\alpha_{A}}$ can be selected to calibrate the infiltration curve of different measuring points. Based on the calibration principle, the selected calibration factor $\mathrm{X}$ and formula (6) are combined to obtain the relationship between the cumulative infiltration quantity and the infiltration time of any measurement points in the region:

$$
I^{\#}=5.8397 \alpha_{A}{ }^{0.5} t^{\# 0.5}+0.4475 \alpha_{A}{ }^{2} t^{\#}
$$

\subsection{Analysis of variation characteristics of calibration factor $\alpha_{A}$ space.}

Equation (7) contains only one unknown quantity, Therefore, it is necessary to analyze its spatial variation characteristics to reflect the spatial variation characteristics of soil infiltration. SPSS software was used for statistical analysis of 12 sets of $\alpha_{A}$ values obtained from measured data. The results are shown in table 2, According to the data in the table, the calibration factor $\alpha_{A}$ is the skewed distribution, with the variation coefficient of 0.3234 , indicating that the calibration factor $\sigma_{A}$ in the selected region has certain spatial variation characteristics.

Table 2 Statistical results of scaling factor $\boldsymbol{\alpha}_{A}$

\begin{tabular}{|c|c|}
\hline Measuring point number & 12 \\
\hline Distribution type & Skewness distribution \\
\hline The maximum value & 1.7 \\
\hline The minimum value & 0.1 \\
\hline The average & 0.8494 \\
\hline standard deviation & 0.5512 \\
\hline skewness & -0.043 \\
\hline
\end{tabular}

\begin{tabular}{|c|c|}
\hline kurtosis & -1.579 \\
\hline Coefficient of variation & 0.3234 \\
\hline
\end{tabular}

\section{Conclusion}

Philip's formula can better describe the water infiltration characteristics in the field. On the basis of calibration theory, Philip's formula is calibrated. It turns out that $\boldsymbol{\alpha}_{A}$ is the best, And based on it, the formula of the optimal calibration calculation for the cumulative infiltration of soil in the experimental plot of the west campus of tianjin agricultural college is obtained. The analysis results show that the calibration factor $\boldsymbol{\alpha}_{A}$ has a certain degree of spatial variation.

\section{References}

1. Lei ,Z.D.,Yang S.X,Xie S.C. One-step method of scaling the soil hydraulic properties in the filed [J]. Journal of Hydraulic Engineering,1986,17 (12) : 1 10.

2. Huang ,G.H. A review of experimental study on spatial variability of soil hydraulic properties [J] . Advance in WaterScience,1999,10( 4) : 450- 457.

3. Li,X.Y,Lei ,T.W,Wang W. Spatial variability of field soil properties and Kriging method[J]. Agric.Borealioccidentalis,2000,28( 6) : 30- 35.

4. Bai, M.J, Xu D, Li,Y.N, Li,J.S. Study on spatiotemporal variability of soil infiltration parameters in ground irrigation [J].Journal of soil and water conservation, 2005,19 (5):120-151

5. Yuan,J.P. Zhang,S.L. Zhang,C.Y. Jiang,D.S. Spatial variation of soil stability infiltration rate in small watershed in loess hilly region [J]. Journal of soil science, 2001,38 (4) 579-583

6. Jia,H.W. Kang,S.Z. Zhang,F.C. Tong,L Yao,L.M. Study on spatial variation of soil infiltration characteristics in plain area of Shiyang river basin [J]. Advance in Water Science, 2006,17(4) 471-476

7. He,D. Ma,D.H. Zhang,X.Z. Zhang,J.B. Zheng, Z.C. Spatial variation of soil infiltration characteristics and its source of variation [J]. Water science progress, 2013,24 (3) 340-348

8. Nie,W.B. FeiL.J. Ma, X.Y. Study on Spatial Variability of Infiltration Characteristics in Yangling District[J]. Soils, 2013, 45(1): 152-158. 